\title{
Prognostic Significance of Blood Glucose Levels and Alterations Among Patients with Aluminium Phosphide Poisoning
}

$$
\text { دلالة مستويات الجلوكوز في الدم وتغيراته كعوامل تنبؤ بنتائج المرضى المصابين }
$$

أرفند شارما، براسانث بـالاسبرامينين، كيران جل، أشيش بلّه

ABSTRACT: Objectives: This study aimed to assess the prognostic significance of blood glucose levels and blood glucose alterations (i.e. hyper- or hypoglycaemia) among patients with aluminium phosphide (AIP) poisoning. Methods: This prospective observational study was conducted at the Postgraduate Institute of Medical Education \& Research, Chandigarh, India, between January 2010 and June 2011. All patients presenting to the emergency department with a definitive history of AlP ingestion or symptoms compatible with AlP poisoning were included in the study. Blood glucose levels were recorded at presentation and every six hours thereafter. Alterations in blood glucose levels and other clinical and laboratory variables were subsequently compared between survivors and non-survivors. Results: A total of 116 patients with AlP poisoning were identified. Of these, 57 patients (49\%) survived and 59 patients (51\%) died. At presentation, the mean blood glucose levels of survivors and non-survivors were $119.9 \pm 35.7 \mathrm{mg} / \mathrm{dL}$ and $159.7 \pm 92.5 \mathrm{mg} / \mathrm{dL}$, respectively $(P<0.001)$. In comparison to the survivors, non-survivors had significantly higher heart rates, total leukocyte counts, blood glucose level alterations and serum creatinine levels $(P<0.050)$. In addition, systolic blood pressure, Glasgow coma scale scores, arterial blood gas $\mathrm{pH}$ and bicarbonate values and duration of hospital stay was significantly lower compared to survivors $(P<0.001)$. However, neither blood glucose levels at admission nor blood glucose alterations correlated independently with mortality in a multivariate analysis. Conclusion: The role of blood glucose level alterations in predicting patient outcomes in AlP poisoning cases remains inconclusive. Further studies with larger sample sizes are required.

Keywords: Aluminum Phosphide; Poisoning; Blood Glucose; Hyperglycemia; Hypoglycemia; Mortality; Prognostic Factors; India.

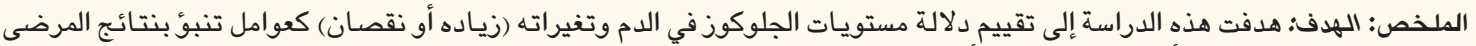

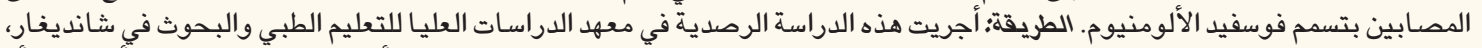

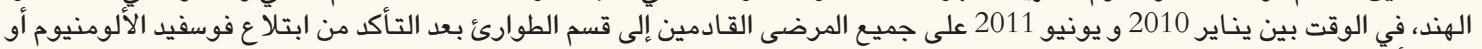

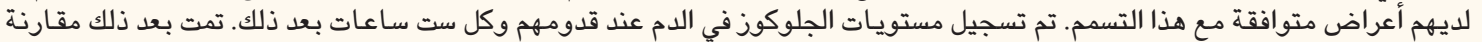

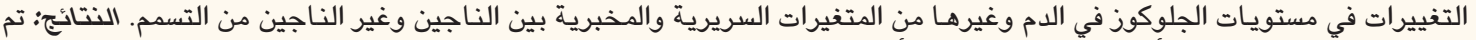

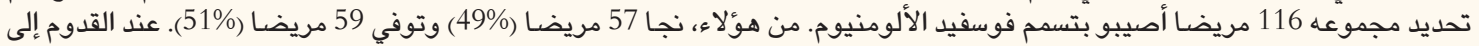

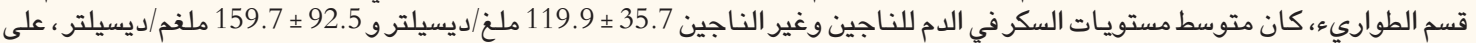

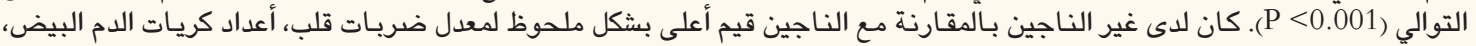

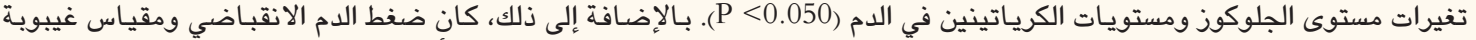

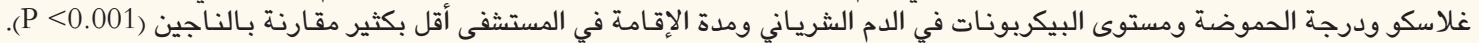

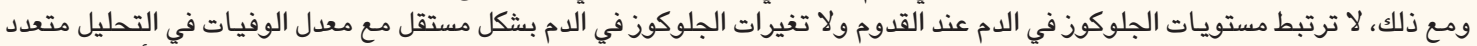

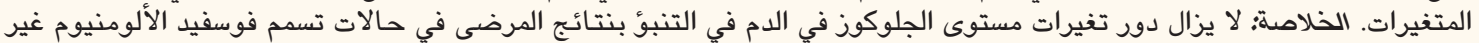

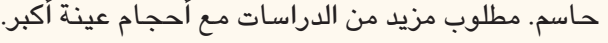
الكلمات المفتاحية: تسمم فوسفيد الألومنيوم؛ جلوكوز الدم؛ ارتفاع السكر في الدم؛ نقص السكر في الدم؛ معدل الوفيات؛ عوامل التنبؤ؛ الهند.

\section{ADVANCES IN KNOWLEDGE}

Elevated blood glucose levels have been previously identified as an indicator of poor prognosis in cases of aluminium phosphide (AlP) poisoning. However, the currentstudy found that blood glucose level alterations-namely, hyper-or hypoglycaemia-were not associated with mortality in AlP cases.

\section{Application to Patient Care}

Based on the findings of the current study, blood glucose level alterations should not be considered predictors of poor patient prognosis in AlP poisoning cases. Patients should therefore be assessed based on a range of clinical and laboratory parameters. 
$\mathrm{I}$ N INDiA, ALUMiniUm PhOSPhide (ALP) IS THE most commonly encountered poison after anticholinesterase. ${ }^{1}$ As a pesticide, AlP is used extensively to protect stored products and crops and is available in the form of pellets, tablets or compressed discs. In northern India, an epidemic of AlP poisoning was reported in 1988 in which 285 cases of AlP ingestion were documented, most of which were intentional/ suicidal. ${ }^{2}$ Although the toxicokinetic properties of AlP are poorly understood, its toxicodynamic properties are exerted by phosphine $\left(\mathrm{PH}_{3}\right)$, which is released in the stomach when it comes into contact with moisture or hydrochloric acid and results in the inhibition of cytochrome $\mathrm{C}$ oxidase and a release of free oxygen radicals, causing oxidative stress. ${ }^{3,4}$ After oral ingestion, $\mathrm{PH}_{3}$ is quickly absorbed into the body, resulting in systemic toxicity, with death usually resulting from cardiovascular dysfunction. ${ }^{5}$ Phosphides may also be absorbed in their unhydrolysed salt form. ${ }^{6}$

Apart from a definitive history of ingestion, a diagnosis of AlP poisoning can be established by the odour of the patient's breath, which often smells of garlic or decaying fish, although the former symptom is also seen in calcium carbide poisoning cases..$^{7-9}$ Other early symptoms include nausea, vomiting, epigastric and retrosternal pain, anxiety, agitation and dyspnoea. ${ }^{7}$ In addition, the diagnosis can also be made by silver nitrate testing of the gastric fluid or breath. ${ }^{9}$ Peripheral circulatory failure and shock are early signs indicating fatal toxicity. ${ }^{7}$ The mortality rate in AlP poisoning cases varies from $30-100 \%$ and depends upon the dose and freshness of the poison, the onset of clinical manifestations, time until presentation, duration and severity of shock, time until vomiting and treatment modality. The main complications observed in fatal AlP poisoning cases are cardiac dysrhythmias, severe metabolic acidosis, shock, respiratory distress syndrome and hypomagnesaemia. ${ }^{7}$

Prognostic factors that may predict poor outcomes in AlP poisoning cases include hyperglycaemia, hypotension, acidosis, leukocytosis, hyperuricaemia, electrocardiography abnormalities, high Acute Physiology and Chronic Health Evaluation scores, high Simplified Acute Physiology Scores, low Glasgow coma scale scores, acute renal failure, low prothrombin rates, methaemoglobinaemia and the use of inotropes and mechanical ventilation. ${ }^{10-14}$ Serial blood glucose monitoring is a convenient and easy method of assessing hypo- or hyperglycaemia, particularly in primary healthcare settings with limited resources. The current study aimed to determine the incidence of blood glucose level alterations in patients with AlP poisoning and the correlations between blood glucose levels and alterations and mortality.

\section{Methods}

This prospective observational study was conducted at the Postgraduate Institute of Medical Education \& Research, a tertiary referral centre in Chandigarh, northeast India, from January 2010 to June 2011. All patients presenting to the emergency department during this period with a definitive history of AlP ingestion or symptoms compatible with AlP poisoning_-including vomitus smelling of decaying fish or garlic, severe hypotension or shock, metabolic acidosis and abnormalities in cardiac rate or rhythm-were included in the study. Cases in which the ingestion of AlP was doubtful or with concomitant ingestion of other drugs or alcohol were excluded, as were patients with a history of dextrose administration prior to presentation or those with diabetes mellitus.

The vital signs of the patients were assessed, including their blood pressure (BP), heart rate and respiratory rate. Temperature and oxygen saturation were recorded using a pulse oximeter. Blood glucose levels were recorded using the Hitachi Modular Analytics System P800 chemistry analyser (Roche Diagnostics K.K., Tokyo, Japan), after appropriate calibration and quality control measures. Alterations in blood glucose levels were defined as the occurrence of either hyperglycaemia (random blood glucose levels of $>200 \mathrm{mg} / \mathrm{dL}$ ) or hypoglycaemia (random blood glucose levels of $<55 \mathrm{mg} / \mathrm{dL}$ ) at admission or any point during hospital stay. ${ }^{15,16}$ A complete blood count was performed along with biochemical tests to determine serum sodium, potassium, urea, creatinine and bilirubin levels. Arterial blood gas (ABG) analyses were performed to determine $\mathrm{pH}$, partial pressure of oxygen, bicarbonate value, partial pressure of carbon dioxide and base excess for the given fraction of inspired oxygen. All clinical and laboratory measurements were recorded at admission, every six hours thereafter for the first 72 hours and then every 24 hours until discharge. If necessary, certain variables were assessed more frequently, depending on the clinical condition of the patient.

All patients received standard supportive treatment, including basic emergency medical care and gastrointestinal decontamination (i.e. gastric lavage). Hypoglycaemic patients were treated with rapid intravenous infusions of two units of $100 \mathrm{~mL}$ of $25 \%$ dextrose solution and then maintained with $5 \%$ dextrose or $5 \%$ dextrose and normal saline solution, titrated according to electrolyte levels and glycaemic status. ${ }^{17,18}$ A maximum of two units of 5\% dextrose and normal saline solution up to a total of $500 \mathrm{~mL}$ daily were administered as a maintenance regimen for euglycaemic patients, titratred according to the patient's input-output status. Hyperglycaemic patients were treated initially according 
Table 1: Characteristics of patients with aluminium phosphide poisoning $(\mathrm{N}=116)$

\begin{tabular}{|c|c|c|c|}
\hline \multirow[t]{2}{*}{ Variable } & \multicolumn{2}{|c|}{ Mean \pm SD } & \multirow[t]{2}{*}{$P$ value } \\
\hline & $\begin{array}{l}\text { Survivors } \\
(\mathrm{n}=57)\end{array}$ & $\begin{array}{l}\text { Non- } \\
\text { survivors } \\
(\mathrm{n}=59)\end{array}$ & \\
\hline \multicolumn{4}{|c|}{ Sociodemographic characteristic } \\
\hline Age in years & $28 \pm 9$ & $30 \pm 11$ & 0.399 \\
\hline Male gender, n (\%) & $38(67)$ & $33(56)$ & 0.235 \\
\hline \multicolumn{4}{|c|}{ Form of AlP ingested, $\mathbf{n}(\%)$} \\
\hline Powder & $40(70)$ & $51(86)$ & \\
\hline Tablet & $11(19)$ & $3(5)$ & 0.051 \\
\hline Unknown & $6(11)$ & $5(9)$ & \\
\hline \multicolumn{4}{|c|}{ Vital signs at admission } \\
\hline Heart rate in bpm & $101 \pm 14$ & $109 \pm 11$ & 0.001 \\
\hline $\mathrm{SBP}$ in $\mathrm{mmHg}$ & $106 \pm 29$ & $77 \pm 20$ & $<0.001$ \\
\hline Glasgow coma score & $12.9 \pm 0.1$ & $2.3 \pm 0.8$ & $<0.001$ \\
\hline \multicolumn{4}{|c|}{ Blood glucose measurements } \\
\hline $\begin{array}{l}\text { Blood glucose level" } \\
\text { in } \mathrm{mg} / \mathrm{dL}\end{array}$ & $119.9 \pm 35.7$ & $159.7 \pm 92.5$ & $<0.001$ \\
\hline $\begin{array}{l}\text { Frequency of blood } \\
\text { glucose alterations, } \\
\text { n (\%) }\end{array}$ & $3(5)$ & $25(42)$ & $<0.001^{\ddagger}$ \\
\hline \multicolumn{4}{|l|}{ Biochemistry results } \\
\hline $\begin{array}{l}\text { Serum sodium in } \\
\mathrm{mmol} / \mathrm{L}\end{array}$ & $142.5 \pm 7.0$ & $144.6 \pm 7.4$ & 0.058 \\
\hline $\begin{array}{l}\text { Serum potassium in } \\
\mathrm{mmol} / \mathrm{L}\end{array}$ & $4.0 \pm 0.7$ & $4.1 \pm 1.1$ & 0.216 \\
\hline $\begin{array}{l}\text { Serum creatinine in } \\
\mathrm{mg} / \mathrm{dL}\end{array}$ & $0.8 \pm 1.0$ & $1.4 \pm 1.2$ & 0.003 \\
\hline $\begin{array}{l}\text { Serum bilirubin in } \\
\mathrm{mg} / \mathrm{dL}\end{array}$ & $0.9 \pm 0.6$ & $0.8 \pm 0.5$ & 0.116 \\
\hline TLC $\times 10^{3}$ per $\mathrm{mm}^{3}$ & $8.6 \pm 3.4$ & $12.2 \pm 5.1$ & 0.005 \\
\hline \multicolumn{4}{|l|}{ ABG measurements } \\
\hline $\mathrm{pH}$ & $7.3 \pm 0.7$ & $7.1 \pm 1.3$ & $<0.001$ \\
\hline $\mathrm{HCO}_{3}$ & $16.3 \pm 4.8$ & $11.3 \pm 5.6$ & $<0.001$ \\
\hline \multicolumn{4}{|c|}{ Presentation/hospital stay characteristics } \\
\hline $\begin{array}{l}\text { Median interval } \\
\text { between ingestion } \\
\text { and presentation in } \\
\text { hours (IQR) }\end{array}$ & $4(3-6)$ & $4(2-7)$ & $0.816^{\S}$ \\
\hline $\begin{array}{l}\text { Median dextrose } \\
\text { administered in } g \\
\text { (IQR) }\end{array}$ & $62(25-125)$ & $75(43-106)$ & $0.856^{\S}$ \\
\hline $\begin{array}{l}\text { Median LOS in } \\
\text { hours (IQR) }\end{array}$ & $36(24-66)$ & $5(2-12)$ & $<0.001^{\S}$ \\
\hline \multicolumn{4}{|c|}{$\begin{array}{l}S D=\text { standard deviation; } A l P=\text { aluminium } \text { phosphide; } \text { bpm = beats } \\
\text { per minute; } S B P=\text { systolic blood pressure; TLC = total leukocyte count; } \\
A B G=\text { arterial blood gas; } H C O_{3}=\text { bicarbonate; } I Q R=\text { interquartile } \\
\text { range; } L O S=\text { length of stay. }\end{array}$} \\
\hline \multicolumn{4}{|c|}{$\begin{array}{l}\text { "Assessed via random blood glucose tests. }{ }^{\dagger} \text { Defined as either hyper- } \\
\text { glycaemia (random blood glucose levels of }>200 \mathrm{mg} / \mathrm{dL} \text { ) or hypo- } \\
\text { glycaemia (random blood glucose levels of }<55 \mathrm{mg} / \mathrm{dL} \text { ). }{ }^{\ddagger} \text { Using a } \\
\text { Mann-Whitney U test. }{ }^{\$} \text { Using a Chi-squared test. }\end{array}$} \\
\hline
\end{tabular}

to a continuous insulin infusion protocol and, subsequently, via a subcutaneous insulin regimen. ${ }^{19}$

The statistical analysis was performed using the Statistical Package for the Social Sciences (SPSS), Version 22.0 (IBM Corp., Armonk, New York, USA). Various clinical and laboratory parameters were compared between survivors and non-survivors, with the primary variables of interest being blood glucose level at presentation and the frequency of blood glucose alterations at admission or during hospital stay. The normality of quantitative variables was determined using the KolmogorovSmirnov test. For normally distributed data, means and standard deviations were calculated for continuous variables while frequencies, percentages and proportions were calculated for qualitative variables. A t-test was used to compare the mean differences between the study groups and a Chi-squared test was used to compare proportions. Univariate and multivariate logistic regression analyses were conducted with mortality as the dependent variable. Independent variables found to be significant on the univariate analysis were included in the logistic regression model and analysed using the Enter method. Random blood glucose levels were considered to be a continuous variable in the univariate and multivariate regression analyses, whereas alterations in blood glucose levels were considered categorical (i.e. nominal) variables. A $P$ value of $<0.050$ was considered statistically significant.

This study was conducted with prior approval from the institutional ethics committee. Written informed consent was obtained from all patients or their relatives prior to participation in the study.

\section{Results}

A total of 116 cases of AlP poisoning were identified. Of these, 59 patients (51\%) were $15-25$ years old, 32 (28\%) were $26-35$ years old, 14 (12\%) were $36-45$ years old, nine (8\%) were $46-55$ years old and two (2\%) were over 55 years old. The most frequent symptoms were vomiting (99\%) and epigastric pain (61\%), followed by dyspnoea (41\%) and altered sensorium (28\%). The median length of hospital stay was 18 hours (range: 5-42 hours). At presentation, 12 (10\%) patients had hypoglycaemia, $16(14 \%)$ had hyperglycaemia and 88 (76\%) had normal blood glucose levels.

In total, 57 patients (49\%) survived and 59 patients (51\%) died. The cause of death was refractory cardiogenic shock in 20 patients (34\%), multiorgan dysfunction syndrome in six patients (10\%), cardiac arrhythmias in five patients $(8 \%)$ and respiratory failure in four patients (7\%). The cause of death in the remaining 24 cases $(41 \%)$ could not be determined. In terms of blood glucose alterations, all of the patients with hyperglycaemia, nine patients (75\%) 
Table 2: Logistic regression model to predict mortality among patients with aluminium phosphide poisoning $(\mathrm{N}=116)$

\begin{tabular}{|c|c|c|c|c|}
\hline Predictor & $\begin{array}{l}\text { Regression } \\
\text { coefficient }\end{array}$ & SE & $\begin{array}{c}\text { OR } \\
(95 \% \mathrm{CI})\end{array}$ & $\begin{array}{c}P \\
\text { value }\end{array}$ \\
\hline Heart rate & -0.009 & 0.050 & $\begin{array}{c}0.991 \\
(0.899-1.093)\end{array}$ & 0.860 \\
\hline SBP & -0.080 & 0.037 & $\begin{array}{c}0.923 \\
(0.859-0.992)\end{array}$ & 0.029 \\
\hline $\begin{array}{l}\text { Glasgow } \\
\text { coma score }\end{array}$ & -0.586 & 0.454 & $\begin{array}{c}0.557 \\
(0.229-1.355)\end{array}$ & 0.197 \\
\hline $\begin{array}{l}\text { Blood glucose } \\
\text { level* }\end{array}$ & 0.012 & 0.009 & $\begin{array}{c}1.012 \\
(0.994-1.031)\end{array}$ & 0.187 \\
\hline $\begin{array}{l}\text { Blood glucose } \\
\text { alterations }{ }^{\dagger}\end{array}$ & 2.036 & 1.544 & $\begin{array}{c}7.662 \\
(0.372-157.919)\end{array}$ & 0.187 \\
\hline $\begin{array}{l}\text { Serum } \\
\text { creatinine } \\
\text { level }\end{array}$ & 0.293 & 0.594 & $\begin{array}{c}1.340 \\
(0.418-4.294)\end{array}$ & 0.623 \\
\hline TLC & 0.000 & 0.000 & $\begin{array}{c}1.000 \\
(1.000-1.000)\end{array}$ & 0.913 \\
\hline ABG pH & -1.760 & 3.620 & $\begin{array}{c}0.172 \\
(0.000-207.369)\end{array}$ & 0.627 \\
\hline $\mathrm{ABG} \mathrm{HCO}_{3}$ & -0.045 & 0.135 & $\begin{array}{c}0.956 \\
(0.734-1.246)\end{array}$ & 0.741 \\
\hline $\begin{array}{l}\text { Duration of } \\
\text { LOS }\end{array}$ & -0.094 & 0.035 & $\begin{array}{c}0.910 \\
(0.850-0.976)\end{array}$ & 0.008 \\
\hline
\end{tabular}

$S E=$ standard error $; O R=$ odds ratio; $C I=$ confidence interval; $S B P=$ systolic blood pressure; $T L C=$ total leukocyte count; $A B G=$ arterial blood gas; $\mathrm{HCO}_{3}=$ bicarbonate; $\mathrm{LOS}=$ length of stay.

*Assessed via random blood glucose tests. ${ }^{\dagger}$ Defined as either hyperglycaemia (random blood glucose levels of $>200 \mathrm{mg} / \mathrm{dL}$ ) or hypoglycaemia (random blood glucose levels of $<55 \mathrm{mg} / \mathrm{dL}$ ).

with hypoglycaemia and 34 patients (39\%) with normal blood glucose levels died.

Both mean blood glucose levels $(159.7 \pm 92.5 \mathrm{mg} / \mathrm{dL}$ versus $119.9 \pm 35.7 \mathrm{mg} / \mathrm{dL} ; P<0.001)$ and the frequency of blood glucose alterations ( $5 \%$ versus $42 \%$; $P<0.001$ ) were significantly higher among non-survivors compared to survivors. This was also the case for heart rate (109 \pm 11 beats per minute [bpm] versus $101 \pm 14 \mathrm{bpm}$; $P=0.001)$, total leucocyte count $\left(12.2 \pm 5.1 \times 10^{3}\right.$ per $\mathrm{mm}^{3}$ versus $8.6 \pm 3.4 \times 10^{3}$ per $\left.\mathrm{mm}^{3} ; P=0.005\right)$ and serum creatinine levels $(1.4 \pm 1.2 \mathrm{mg} / \mathrm{dL}$ versus $0.8 \pm 1.0 \mathrm{mg} / \mathrm{dL}$; $P=0.003)$. In addition, non-survivors had significantly lower systolic BP at admission $(77 \pm 20 \mathrm{mmHg}$ versus $106 \pm 29 \mathrm{mmHg})$, Glasgow coma scale scores $(2.3 \pm 0.8$ versus $12.9 \pm 0.1)$, arterial blood gas $\mathrm{pH}(7.1 \pm 1.3$ versus $7.3 \pm 0.7)$ and bicarbonate values $(11.3 \pm 5.6$ versus $16.3 \pm 4.8)$ and median duration of hospital stay (5 versus 36 hours) compared to survivors $(P<0.001$ each) [Table 1].

Statistically significant variables from the univariate analysis were subsequently included in a logistic regression model to predict mortality at a $95 \%$ confidence interval. Although systolic BP at admission $(P=0.029)$ and duration of hospital stay $(P=0.008)$ remained significant, neither blood glucose levels nor blood glucose alterations were found to be independent predictors of mortality $(P>0.050$ each $)$ [Table 2 ].

\section{Discussion}

According to international recommendations, blood glucose levels should be maintained at $140-180 \mathrm{mg} / \mathrm{dL}$ for normoglycaemic patients and 180-200 mg/dL for previously diabetic individuals. ${ }^{20}$ Both the hypoand hyperglycaemic effects of AlP are attributable to the wide variety of changes in magnesium, calcium, phosphate, citrate and cortisol levels that result from AlP poisoning. ${ }^{11,21}$ These biochemical changes can act as either stimulatory or inhibitory modulators of the enzymes and hormones that catalyse and regulate the metabolism of glucose. Therefore, depending on the type of biochemical change, AlP poisoning can result in the elevation or decrease of blood glucose levels or neither. ${ }^{11,21}$

Nevertheless, the specific mechanism by which AlP poisoning causes hypoglycaemia is poorly understood. Possible explanations include as a result of liver damage due to the release of $\mathrm{PH}_{3}$ gas and the toxic effects of $\mathrm{PH}_{3}$ on the adrenal cortex, leading to decreased cortisol levels. ${ }^{22}$ In addition, certain symptoms of AlP poisoning such as recurrent vomiting and lack of appetite may also play a role in the development of hypoglycaemia. In contrast, hyperglycaemia occurs due to either the stimulation of cortisol, glucagon and adrenaline secretion or the inhibition of insulin synthesis. ${ }^{11,21}$ A glucoseinsulin-potassium infusion has been suggested as a potential therapeutic modality in the treatment of hyperglycaemia in AlP poisoning. ${ }^{23}$

Among critically-ill patients, blood glucose alterations have been associated with prolonged hospital stays as well as increased mortality. ${ }^{20,24}$ However, to the best of the authors' knowledge, only one previous study has examined the relationship between hyperglycaemia and AlP poisoning outcomes. Mehrpour et al. published a prospective study of 45 patients with acute AlP poisoning, of which 32 patients (71\%) died. ${ }^{11}$ Non-survivors had significantly higher mean blood glucose levels than survivors $(222.6 \pm 20 \mathrm{mg} / \mathrm{dL}$ versus $143.4 \pm 13.7 \mathrm{mg} / \mathrm{dL}$; $P=0.021)$. Furthermore, blood glucose levels were an independent predictor of mortality in a multivariate analysis. ${ }^{11}$ This contradicts the findings of the current study in which alterations in blood glucose levels (i.e. either hyperglycaemia or hypoglycaemia) were not independent predictors of mortality. This may be because Mehrpour et al. utilised a different cutoff value to indicate hyperglycaemia than that of the present study $(>140 \mathrm{mg} / \mathrm{dL}$ versus $>200 \mathrm{mg} / \mathrm{dL}) .{ }^{11}$ 
Strengths of the current study include its sample size and the evaluation of both hyper- and hypoglycaemia as predictors of mortality. However, the results are limited by the absence of any long-term follow-up of the survivors and the lack of analysis of other factors which may play a role in glucose homeostasis, such as serum calcium, magnesium, phosphate, insulin and cortisol levels.

\section{Conclusion}

As a result of several complex mechanisms, AlP poisoning can cause both hyper- and hypoglycaemia. However, the role of blood glucose levels and blood glucose alterations in predicting patient outcomes in AlP poisoning cases remains inconclusive. The authors recommend that further studies with larger sample sizes be conducted to evaluate other factors involved in glucose homeostasis.

\section{CONFLICT OF INTEREST}

The authors declare no conflicts of interest.

\section{FUNDING}

No funding was received for this study.

\section{References}

1. Murali R, Bhalla A, Singh D, Singh S. Acute pesticide poisoning: 15 years experience of a large north-west Indian hospital. Clin Toxicol (Phila) 2009; 47:35-8. doi: 10.1080/15563650701885807.

2. Banjaj R, Wasir HS. Epidemic aluminium phosphide poisoning in Northern India. Lancet 1988; 1:820-1. doi: 10.1016/S0140-6736 (88)91676-5

3. Price NR, Mills KA, Humphries LA. Phosphine toxicity and catalase activity in susceptible and resistant strains of lesser grain borer (Rhyzopertha dominica). Comp Biochem Physiol C Pharmacol Toxicol Endocrinol 1982; 73:411-13. doi: 10.1016/03064492(82)90144-7.

4. Bolter CJ, Chefurka W. Extramitochondrial release of hydrogen peroxide from insect and mouse liver mitochondria using the respiratory inhibitors phosphine, myxothiazol, and antimycin and spectral analysis of inhibited cytochromes. Arch Biochem Biophys 1990; 278:65-72. doi: 10.1016/0003-9861(90)90232-N.

5. Burgess JL, Morrissey B, Keifer MC, Robertson WO. Fumigantrelated illnesses: Washington State's five-year experience. J Toxicol Clin Toxicol 2000; 38:7-14. doi: 10.1081/CLT-100100909.

6. Curry AS, Price DE, Tryhorn FG. Absorption of zinc phosphide particles. Nature 1960; 184:642-3. doi: 10.1038/184642a0.

7. Mehrpour O, Jafarzadeh M, Abdollahi M. A systematic review of aluminium phosphide poisoning. Arh Hig Rada Toksikol 2012; 63:61-73. doi: 10.2478/10004-1254-63-2012-2182.

8. Chugh SN, Ram S, Chugh K, Malhotra KC. Spot diagnosis of aluminium phosphide ingestion: An application of a simple test. J Assoc Physicians India 1989; 37:219-20.
9. European Food Safety Authority. Conclusion on the peer review of the pesticide risk assessment of the active substance calcium carbide. Eur Food Saf Author J 2011; 9:2419. doi: 10.2903/j. efsa.2011.2419.

10. Bogle RG, Theron P, Brooks P, Dargan PI, Redhead J. Aluminium phosphide poisoning. Emerg Med J 2006; 23:e3. doi: 10.1136/ emj.2004.015941.

11. Mehrpour O, Alfred S, Shadnia S, Keyler DE, Soltaninejad K, Chalaki N, et al. Hyperglycemia in acute aluminum phosphide poisoning as a potential prognostic factor. Hum Exp Toxicol 2008; 27:591-5. doi: 10.1177/0960327108096382.

12. Mostafazadeh B, Pajoumand A, Farzaneh E, Aghabiklooei A, Rasouli MR. Blood levels of methemoglobin in patients with aluminum phosphide poisoning and its correlation with patient's outcome. J Med Toxicol 2011; 7:40-3. doi: 10.1007/s13181-0100121-7.

13. Shadnia S, Mehrpour O, Soltaninejad K. A simplified acute physiology score in the prediction of acute aluminum phosphide poisoning outcome. Indian J Med Sci 2010; 64:532-9.

14. Louriz M, Dendane T, Abidi K, Madani N, Abouqal R, Zeggwagh AA. Prognostic factors of acute aluminum phosphide poisoning. Indian J Med Sci 2009; 63:227-34. doi: 10.4103/0019-5359.53386.

15. Qaseem A, Humphrey LL, Chou R, Snow V, Shekelle P. Use of intensive insulin therapy for the management of glycemic control in hospitalized patients: A clinical practice guideline from the American College of Physicians. Ann Intern Med 2011; 154:260-7. doi: 10.7326/0003-4819-154-4-201102150-00007

16. Klonoff DC, Alexander Fleming G, Muchmore DB, Frier BM. Hypoglycemia evaluation and reporting in diabetes: Importance for the development of new therapies. Diabetes Metab Res Rev 2017; 33:e2883. doi: 10.1002/dmrr.2883.

17. Alsahli M, Gerich JE. Hypoglycemia. Endocrinol Metab Clin North Am 2013; 42:657-76. doi: 10.1016/j.ecl.2013.07.002.

18. Cryer PE, Axelrod L, Grossman AB, Heller SR, Montori VM, Seaquist ER, et al. Evaluation and management of adult hypoglycemic disorders: An Endocrine Society clinical practice guideline. J Clin Endocrinol Metab 2009; 94:709-28. doi: 10.1210/jc. 2008-1410.

19. McDonnell ME, Umpierrez GE. Insulin therapy for the management of hyperglycemia in hospitalized patients. Endocrinol Metab Clin North Am 2012; 41:175-201. doi: 10.1016/j.ecl. 2012.01.001

20. Aramendi I, Burghi G, Manzanares W. Dysglycemia in the critically ill patient: Current evidence and future perspectives. Rev Bras Ter Intensiva 2017; 29:364-72. doi: 10.5935/0103507X.20170054.

21. Abder-Rahman H. Effect of aluminum phosphide on blood glucose level. Vet Hum Toxicol 1999; 41:31-2.

22. Chugh SN, Ram S, Sharma A, Arora BB, Saini AS, Malhotra KC. Adrenocortical involvement in aluminium phosphide poisoning. Indian J Med Res 1989; 90:289-94.

23. Hassanian-Moghaddam H, Zamani N. Therapeutic role of hyperinsulinemia/euglycemia in aluminum phosphide poisoning. Medicine (Baltimore) 2016; 95:e4349. doi: 10.1097/MD.000000 0000004349 .

24. Fahy BG, Sheehy AM, Coursin DB. Glucose control in the intensive care unit. Crit Care Med 2009; 37:1769-76. doi: 10.10 97/CCM.0b013e3181a19ceb. 